\title{
Mindfulness and Its Role in Psychological Well-Being
}

\author{
Dorothy A. Sisk \\ Lamar University, Texas, USA
}

\begin{abstract}
This article explores mindfulness, and highlights two major contributors to the development of Mindfulness, a Buddhist Monk Thich Nhat Hanh and a Physician Dr. Jon Kabat Zinn. Mindfulness training programs are discussed and a research study designed to include mindfulness in a residential program for secondary gifted students to examine their role of mindfulness in the psychological well-being is discussed with results and conclusions.
\end{abstract}

Keywords: mindfulness, well-being, wellness, connectedness, deep listening, gifted

Be the change you wish to see in the world.

Gandhi's words remind us that we are our own agents of change. Mindfulness can provide insight to help you to envision and create a new model or approach to your life and way of being. Mindfulness is not a new idea since William James in Principles of Psychology (1950) said, "The faculty of voluntarily bringing back a wandering attention, over and over again, is the very root of judgment, character and will.” (p. 424).

Mindfulness is being aware of what is happening within you and around you with a clear focus of your attention on moment-to-moment experiences in the here and now (Sisk \& Kane, 2017). As you engage in mindfulness activities, you can strengthen your inner awareness and vision. This article will explore mindfulness, mindfulness-based programs and the impact of a research study implementing mindfulness with high ability and gifted secondary students.

Mindfulness has ancient roots. but incredible applications employing mindfulness are being made daily in medicine, business, and education. Two very different people Thich Nhat Hanh, a Vietnamese Buddhist monk and an American medical physician Jon Kabat-Zinn have worked with mindfulness over the last 40 years, with amazing contributions, and their impact on mindfulness will be explored. The first to be discussed is Thich Nhat Hanh.

Thich Nhat Hanh is author of five books in the Mindfulness Essential Series including How to Sit (2014a) with clear and simple directions for exploring mindfulness. The second book How to Relax (2015b) addresses the daily stress that makes us less productive and less happy. In this book Thich Nhat Hanh shares techniques for bringing life back into balance. The third book How to Walk (2015a) reminds us that we touch the Earth with awareness, and the importance of stopping "sleepwalking" to arrive fully in the present moment. The fourth book How to Love (2015c) brings clarity, compassion and humor to the essential question of how to love. The fifth book How to Eat (2014b) tells how the process of eating can be a joyful and sustainable activity,

Dorothy A. Sisk, Ph.D., professor, College of Education and Human Development, Teacher Education Department, Lamar University. 
including preparing the food, and even cleaning up after a meal. He shares how he and another novice young monk cleaned up after over 100 monks without running water, using sand to clean the dishes, and yet they were able to enjoy the process. Thich Nhat Hanh in How to Love (2015c) emphasizes love of the Earth, and he said we can express love of the Earth with each step. You can say:

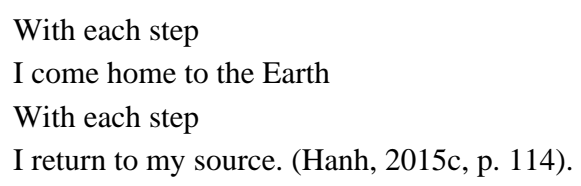

The second individual who has made phenomenal contributions in mindfulness practice is Jon Kabat-Zinn who began working with mindfulness when he established the Mindfulness-Based Stress Reduction (MBSR) clinic at the Massachusetts Medical Center in 1979. The word mindfulness was now here in the medical lexicon at that time; however, today, nearly 23,000 certified MBSR instructors teach mindfulness techniques, including meditation. In addition, there are MBSR clinics in nearly every state in the United States, and in more than 30 countries.

Kabat-Zinn initially worked with treatment resistant patients of other doctors, and after eight weeks of mindfulness training, these treatment resistant patients showed remarkable transformation. Symptom reduction was found in blood pressure, psoriasis, and fibromyalgia, and the patients with chronic pain disorder reported a greater sense of well-being (Kabat-Zinn, 1982; 1998). Several randomized controlled trials and studies showed reduction in psychological morbidity and stress, as well as enhanced emotional well-being (Williams, Kolar, Roger, \& Pearson, 2001). Kabat-Zinn said participants in MBSR training described the mindfulness experience as transformative. (Kabat-Zinn, 2003).

\section{Sense of Connectedness}

Mindfulness builds a sense of connectedness, and a recognition of the similarities of people. With the growing diversity of the population in the United States, it is essential that we develop a respect and connection with others. One powerful mindfulness activity that positively impacts the need for connection is deep listening. Deep listening involves giving full attention to another person and maintaining a present-centered awareness. High ability and gifted students with their many interests and deep passion for individual projects may find deep listening a challenge. Many of them say they give minimal attention to their teachers until they "hear" something they don't already know or that is of interest to them. This behavior can be problematic in student-teacher interaction. All students can benefit from deep listening not only for academic achievement, but for greater social awareness and ability to get along with others. Several mindfulness-based programs have been developed to help develop mindfulness in both students and teachers.

\section{CARE}

Patricia Jennings (2015) a professor from the University of Virginia developed CARE, a mindfulness program for students and teachers. She wanted to promote a wholesome way of learning and living. Jennings emphasized reflecting on one's pattern of behavior, thoughts, and emotions in journals. She said as we engage in reflection, the benefit and importance of taking responsibility for building positive interactions will become apparent. 


\section{Transformative Life Skills}

Jennifer Frank, a professor at Penn State University collaborated with Niroga Institute to develop a program called Transformative Life Skills (TLS). This program emphasizes mindful yoga, breathing techniques, and meditation. This three-core practice involves action, breathing and centering. Action is experienced in mindful movement and yoga postures; breathing exercises help manage stress; and centering brings awareness to

the present moment. A pilot study with 49 high-risk high school students engaged in TLS found the program reduced student stress and improved their well-being (Frank, Bose, \& Schrobenhauser-Clonan, 2014).

\section{Learning to Breathe}

Patricia Broderick (2013) developed Learning to Breathe, a program based on six themes following the acronym BREATHE. $\mathrm{B}$ is for body awareness, $\mathrm{R}$ is for reflection, understanding, and working with your thoughts, E is for understanding and working with your feelings, A is for integrating awareness of your thoughts, feelings, and bodily sensations, $\mathrm{T}$ is for tenderness, taking it as it is, and reducing harmful self-judgment of yourself and others, $\mathrm{H}$ is for habits for a healthy mind, integrating mindful awareness into daily life, and E is for empowerment. Metz et al. (2013) found high school students engaged in Learning to Breathe reported lower stress levels, negative affect, and psychosomatic complaints, and increased levels of efficacy and emotional regulation.

\section{Inner Kids}

Susan Kaiser-Greenland designed the Inner Kids program with a focus on attention, balance and compassion. She wanted participants to develop awareness of their inner experiences, thoughts, emotions, and physical sensations; awareness of outer experiences of other people, places and things; and the importance of how these two inner and outer experiences blend together. Inner Kids was found to be particularly helpful in working with students (Flook et al., 2010). In addition, Inner Kids addressed the emotional issues that students experience.

\section{MindUp}

The MindUp program was developed by the Hawn foundation when actress Goldie Hawn lived in Vancouver. The program focuses on four areas: (1) How Our Brains Work; (2) Sharpening Your Senses; (3) It's All About Attitude; and (4) Taking Action Mindfully. MindUp is integrated into most elementary schools in the southern mainland of British Columbia, Canada, and was adopted by the city of Newark, New Jersey. Kimberly Schonert-Reichl conducted several research studies of MindUp and reported that students in the program were more optimistic and self-confident, and their teachers said they demonstrated more social competence (Schonert-Reichl \& Lawlor, 2010).

\section{Kripalu Schools}

Kripalu Yoga in Schools (KYSIS) is a program that works to help participants learn social and emotional regulation, stress management, self-appreciation, self-confidence, and relationship skills. A pilot study of the KYSIS program integrated yoga and mindfulness activities into the regular high school program with high school students. An evaluation of the pilot study was conducted by Noggle, Steiner, Minami, and Khalsa 
(2012). They found the students showed improvement in mood disturbances and lessened anxiety.

\section{Mindfulness Activities With High School Gifted Students}

The Texas Governor's School (TGS), a three-week residential summer program for high achieving and high ability students from throughout the state of Texas was established in 1990 at Lamar University in Beaumont, Texas. The staff and director decided to plan and implement a mindfulness program for the 73 students attending the 1917 TGS program using the evidence-based research and suggested activities of five Mindfulness programs (Kripalu Yoga, MindUp, Breathe, Inner Kids, and Transformative Life Skills. Specific activities were selected including Awareness Breathing, Belly Breathing, Mindful Walking, Mindful Movement, Mindful Eating, Visualization, and Loving Kindness Meditations.

Awareness Breathing encouraged the students to watch and become aware of breathing in and out. They breathed in at a count of 1-2-3, held the breath 1-2-3 and exhaled 1-2-3.

Belly Breathing asked the student to place a stuffed animal or pillow on their stomach and watch and feel it rising and falling with each breath.

Mindful Walking involved the students in walking slowly around the track at the University and concentrating on their deep breathing and paying attention to their senses. They were asked to notice what they were hearing, seeing, smelling, or feeling as they walked. The following gatha suggested by Thich Nhat Hanh (2015a) was used:

Breathing in, I am aware of my feet.

Breathing out, I smile at my feet (p. 112).

Mindful Movement engaged the students in learning several yoga positions, particularly the Sun Salutation which they experienced with their counselors each morning before breakfast.

Mindful Eating involved the students to fully experience tasting a raisin by holding it in their mouth for several minutes before finally chewing and swallowing it. The students also tasted a marshmallow with the same intense concentration. One of their favorite activities was a snack meditation with tangerines in which they ate the tangerine slowly and mindfully as if it were the most important thing for them to do in their life.

Visualization included a number of visualizations provided by Dr. Sisk, the Director including the classic Three Boxes developed and demonstrated by Maslow (1968) and the Wise Seer on the Mountain from the book the Growing Person (Sisk \& Shallcross, 1982).

Loving Kindness Meditations included a number of Loving Kindness mantras using several of Thich Nhat Hanh’s gathas in his five books, and a favorite from Goldstein (2007):

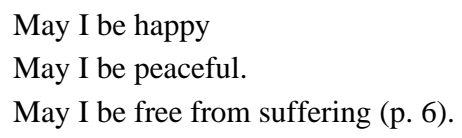

\section{Participants and Methodology}

The participating secondary students ranged in ages from 14-18 and they were enrolled in grades 10-12. The mindfulness sessions were conducted for 30 minutes daily Monday through Sunday. Each student was assigned to an individual counselor who worked with a group of 10-12 students in a "family". The counselors reinforced the mindfulness strategies in evening sessions with their family of students. Observations by the 
Director and the teaching staff indicated that most students were successfully able to block out any noise or distractions during the mindfulness exercises. Dr. Sisk, the Director trained the counselors in the use of the mindfulness strategies in a weekend session, and she conducted the visualization sessions. Each of the students maintained a daily reflective journal in which they wrote about their feelings and thoughts following the mindfulness activities. These entries were examined for themes at the end of the three-week session. Four themes emerged including: (1) a feeling of calmness; (2) sensory awareness; (3) enjoyment; and (4) a sense of peace.

The students were administered a Mindful Attention Awareness Scale developed by Ruth Baer at the University of Kentucky. In addition, the students were administered a Leadership Skills and Behaviors Scale developed by Sisk (1987) that measures self-concept and motivation.

\section{Results}

Pre-test scores in Mindfulness as measured by the Mindful Attention Awareness Scale were 3.95 and post-test scores were 4.28. Pre-test scores in self-concept as measured by the Leadership Skills and Behaviors Scale were 15.33 and post-test scores were 16.92. Motivation as measured by the Leadership Skills and Behaviors Scale pre-test scores were 23.90 and post-test scores were 25.18. Paired $t$ test results showed significant differences in the three test scores at the 0.01 level.

\section{Conclusion}

In our troubled times, mindfulness provides a strategy to reduce anxiety and stress, and mindfulness can be implemented with all students of different abilities. We found that it was important for the staff, teachers, and students to approach the use of mindfulness with an open-heart, present moment, and nonjudgmental awareness. The benefits for both the Texas Governor's School teachers and students was truly life changing. One helpful way for individuals who want to get involved in incorporating mindfulness in their life and in the classroom is to connect with others who are trying to do the same thing. Websites and resources in the references of this article will help get you started, and there are free audio recordings of guided mindfulness practices that you can download. Mindfulness activities and programs can truly transform your life and that of your family or students.

\section{References}

Broderick, P. (2013). Learning to breathe: A mindfulness curriculum for adolescents to cultivate emotion regulation, attention, and performance. Oakland, CA: New Harbinger.

Flook, L., Smalley, S. L., Kitil, M. J., Galla, B., Kaiser Greenland, S., Locke, J., ... Kasari, C. (2010). Effects of mindfulness awareness practices on executive functions in elementary school children. Journal of Applied School Psychology, 26(1).

Frank, J., Bose, B., \& Schrobenhauser-Clonan, A. (2014). Effectiveness of a school-based yoga program on adolescent mental health, stress, coping strategies, and attitudes toward violence. Findings from a high-risk sample. Journal of Applied School Psychology, 50, 29-49.

Goldstein, J. (2007). A heart full of peace. Boston, MA: Wisdom Publications.

Hanh, T. N. (2014a). How to sit. Berkeley, CA: Parallax Press.

Hanh, T. N. (2014b). How to eat. Berkeley, CA: Parallax Press.

Hanh, T. N. (2015a). How to walk. Berkeley, CA: Parallax Press.

Hanh, T. N. (2015b). How to relax. Berkeley, CA: Parallax Press.

Hanh, T. N. (2015c). How to love. Berkeley, CA: Parallax Press.

James. W. (1950). The principles of psychology. New York, NY: Dover. 
Jennings, P. (2015). Mindfulness for teachers. New York, NY: W.W. Norton \& Co.

Kabat-Zinn, J. (1982). An out-patient program in behavioral medicine for chronic pain patients based on the practice of mindful meditation. Clinical Joint Pain, 2, 159-173.

Kabat-Zinn, J. (1998). Meditation. In J. C. Holland (Ed.). Psycho-oncology (pp. 767-79). New York, NY: Oxford University Press.

Kabat-Zinn, J. (2003). Mindfulness-based interventions in context: Past, present and future. Clinical Psychology: Science and Practice, 10(2), 144-156.

Maslow, A. (1968). Toward a psychology of being. Princeton, NJ: Van Nostrand.

Metz, S., Frank, J., Reibel, D., Cantrell, T., Sanders, R., \& Broderick, P. (2013). The effectiveness of the learning to breathe program on adolescent emotion regulation. Research in Human Development, 10, 252-272.

Noggle, J., Steiner, J, Minami, T., \& Khalsa, S. (2012). Benefits of Yoga for psychosocial well-being in a US high school curriculum: A preliminary randomized controlled trial. Journal of Developmental Behavior, 33(3), 193-201.

Schonert-Reichl, K., \& Lawlor, M. (2010). The effects of a mindfulness-based education program on pre and early adolescents' well-being and social and emotional competence. Mindfulness, 1, 137-15l.

Sisk, D. (1987). Leadership skills and behaviors scale. Leadership: A special type of giftedness. Unionville, NY: Trillium Press.

Sisk, D., \& Kane, M. (2017). Planting seeds of mindfulness. New York: NY: Royal Fireworks Press.

Sisk, D., \& Shallcross, D. (1982). The Growing Person. Buffalo, NY: Bearly Limited Press.

Williams, K., Kolar, M., Roger, B., \& Pearson, J. (2001). Evaluation of a wellness-based mindfulness stress reduction intervention: A controlled trial. American Journal of Health Promotion, 15(6), 422-432. 